\title{
Adaptive Protection Coordination Method Design of Remote Microgrid for Three-Phase Short Circuit Fault
}

\author{
Wookyu Chae ${ }^{1}$, Jung-Hun Lee ${ }^{1}$, Woo-Hyun Kim ${ }^{1}$, Sungwook Hwang ${ }^{1}{ }^{\mathbb{D}}$, Jun-Oh Kim ${ }^{2}$ and Jae-Eon Kim ${ }^{3, *}$ (i) \\ 1 Smart Power Distribution Laboratory, Distribution Planning Group, KEPCO Research Institute, \\ Daejeon 34056, Korea; microgrid@kepco.co.kr (W.C.); jh.lee68@kepco.co.kr (J.-H.L.); \\ wh.kim@kepco.co.kr (W.-H.K.); hwangsungwook@kepco.co.kr (S.H.) \\ 2 Korea Electric Power Corporation, Daegu 41590, Korea; kimjunoh@kepco.co.kr \\ 3 School of Electrical Engineering, Chungbuk National University, Cheongju 28644, Korea \\ * Correspondence: jekim@cbnu.ac.kr
}

Citation: Chae, W.; Lee, J.-H.; Kim, W.-H.; Hwang, S.; Kim, J.-O.; Kim, J.-E. Adaptive Protection Coordination Method Design of Remote Microgrid for Three-Phase Short Circuit Fault. Energies 2021, 14 , 7754. https://doi.org/10.3390/ en14227754

Received: 31 August 2021 Accepted: 11 November 2021 Published: 18 November 2021

Publisher's Note: MDPI stays neutral with regard to jurisdictional claims in published maps and institutional affiliations.

Copyright: (c) 2021 by the authors. Licensee MDPI, Basel, Switzerland. This article is an open access article distributed under the terms and conditions of the Creative Commons Attribution (CC BY) license (https:// creativecommons.org/licenses/by/ $4.0 /)$.

\begin{abstract}
Generally, the fault current supplied by inverter-based renewable energy sources (IBRES) and electrical storage systems (ESS) is about 1.2 to 2 times their rated current and much lower than synchronous generators because the former acts as a current source and the latter acts as a voltage source. A conventional power system in a small island is composed of only synchronous generators and protected from short circuit faults using an overcurrent relay (OCR). However, in the remote microgrid with IBRES, ESS, and synchronous generators, the fault current varies depending on the configuration of generation sources. Namely, the fixed OCR protection method cannot protect microgrids from short circuit faults. This paper proposes an adaptive protection method to protect the microgrid from faults by actively changing the OCR setting according to the state of the generator source combination. A microgrid with ESS and a synchronous generator is modeled and simulated through PSCAD/EMTDC software to validate the proposed adaptive protection method.
\end{abstract}

Keywords: remote microgrid; adaptive protection; relay; ESS; renewable energy; short circuit fault

\section{Introduction}

A microgrid (MG) is a small power supply system composed of multiple renewable energy sources, such as wind turbine generation or photovoltaic generation, an electrical storage system (ESS), and a load. It produces and uses power by itself around the load, is generally interconnected with a power system for use, is separated when a problem occurs, and may independently form a system to supply power [1]. However, a small power supply system in an islanded region, etc., which is always separated from the main power system and supplies power by itself, is defined as a remote microgrid [2].

Conventionally, power has been supplied to islanded regions or islands away from the land using remote microgrid technology, and these microgrids have used only diesel generators. However, diesel generator-based remote microgrids have problems such as high costs and environmental pollution due to the use of diesel fuel. Therefore, efforts have been made to supply the power through interconnection with renewable energy, the ESS, etc., and the existing diesel generator to solve such problems [3].

Diesel generator-based remote microgrids cause several problems in terms of protection methods, because multiple synchronous diesel generators are designed to be operated in parallel, and the ESS and renewable energy produced based on an inverter have response properties significantly different from diesel generators. First, since an inverter-based power source uses power-electronics-based switching elements, the magnitude of the fault current that can be supplied compared to a diesel generator with the same capacity is less than $10 \%$. Therefore, sufficient fault current may not be supplied for a protection device to be operated [4-6]. Second, it is difficult to distinguish between an inrush current of a transformer or a motor and a line fault current when the power is supplied using only the 
power source of the inverter. Third, since the number of diesel generators that need to be controlled changes depending upon the ESS's state of charge and the amount of renewable energy generated, the fault current of the microgrid frequently changes. These two reasons may result in the protection device being operated erroneously [7,8]. Recently, as interest in microgrids has increased, various studies have been carried out to solve such problems.

Studies on the fault current properties of remote microgrids with synchronous generators, inverters, wind turbine generators, photovoltaic generators, and distribution feeders have been carried out. It has been demonstrated that it is possible to limit the fault current supplied by the inverter upon a fault in the distribution feeder by adding a current limit function to a grid-forming inverter mounted with a droop property. It has also been demonstrated that the magnitude of the fault current shown in the entire grid differs depending upon whether the synchronous generators are operated in the simulation [9]. This research shows that a fault current limit function could be used to protect a microgrid. At the same time, it does not suggest protection coordination between multiple relays for faults arising at various positions.

A method for installing inverter-based distribution generation and synchronous generator-based distribution together has been proposed to supplement the fault current supply capability of the inverter $[10,11]$. This method has the advantage that protection devices or settings do not need to be changed. However, it does not consider the fault response property in installing an inverter-based power source and a synchronous machinebased one together. Moreover, it does not take into account that the distributed generation installed may not be operated.

It was recognized that the magnitude of the fault current could be changed depending upon the configuration of the microgrid, and an 'adaptive protection method' could be used to frequently change the setting value of the protection relay using an energy management system (EMS). When the configuration or operating method of the microgrid is changed while the EMS is monitoring the state of the microgrid in real-time, the EMS picks up the change, which alters the setting value of the protection relay [12-27]. The adaptive protection method was evaluated as an effective method applicable to the gridinterconnected and stand-alone modes in grid-interconnected microgrids [17]. However, this method changed only the setting value of each relay for the distributed generation to respond to the change in the fault current depending upon the operation mode switching (grid-interconnected or stand-alone) of the microgrid and did not take into account the coordination between multiple relays (for distributed generation, transformer, distribution feeder, etc.) having a multi-layer structure. Further, there were the disadvantages that, with this method, it was difficult to respond appropriately to, such as when communication was lost, thus changing the operation mode of the distributed generation. The prior studies specified above are summarized in Table 1.

As stated earlier, many studies have focused on the changes in fault current properties due to an increase in the inverter-based power source and the switching of the operation mode of the microgrid. However, either only fragmentary studies have been carried out on fault types, or these studies did not sufficiently consider the fault current supply properties of the inverter. Furthermore, studies on protection coordination between the multiple relays installed on most remote microgrids in a multi-layer structure, protection coordination in cases where the synchronous machine must be stopped to maximize the acceptability of the IBRES, changes in the fault current when the control method of the distributed generation is changed, etc., are not sufficient.

This paper proposes an adaptive protection method capable of reliably removing faults in a microgrid even if the configuration and control method of the generator is changed to solve the protection coordination problem caused in remote microgrids. It also proposes an adaptive protection method to actively select a time-current curve(TCC) suitable for various configurations and operation methods for a microgrid to accurately operate only the relay whose operation is required among the relays installed in series, unlike the protection method of conventional single T-C curve in which faults may not 
reliably be detected/isolated depending upon the configuration and operation method of the microgrid.

Table 1. Comparative summary of the proposed solution for microgrid protection issues.

\begin{tabular}{|c|c|c|}
\hline Proposed Protection Method & Claimed Advantages & Disadvantages \\
\hline $\begin{array}{l}\text { Installation of distributed generation } \\
\text { with different properties }[10,11]\end{array}$ & $\begin{array}{l}\text { - Changes to the equipment on protection } \\
\text { or the setting value are not required. }\end{array}$ & $\begin{array}{l}\text { The influence of mutual fault } \\
\text { response properties between the } \\
\text { inverter and the synchronous } \\
\text { machine is not considered. } \\
\text { There are no countermeasures for } \\
\text { when the installed distributed } \\
\text { generation does not operate. }\end{array}$ \\
\hline $\begin{array}{l}\text { Separation of distributed generation } \\
\text { upon the occurrence of a fault }[28,29]\end{array}$ & $\begin{array}{l}\text { - } \quad \text { Relatively inexpensive method. } \\
\text { or the setting value are not required. }\end{array}$ & $\begin{array}{l}\text { - } \quad \text { Occurrence of an outage during } \\
\text { islanding operation of the MG. } \\
\text { - } \quad \text { Applicable only to grid-side faults. }\end{array}$ \\
\hline $\begin{array}{l}\text { Installation of a fault current } \\
\text { limiter }[30,31]\end{array}$ & $\begin{array}{l}\text { - Changes to the equipment on protection } \\
\text { or the setting value are not required. }\end{array}$ & $\begin{array}{l}\text { - Does not respond to changes in the } \\
\text { dynamic configuration of the MG. } \\
\text { - The current limiter is very } \\
\text { expensive. }\end{array}$ \\
\hline $\begin{array}{l}\text { Adaptive protection coordination } \\
\qquad[12-27]\end{array}$ & $\begin{array}{l}\text { - Capable of responding to changes in the } \\
\text { dynamic configuration of the MG. }\end{array}$ & $\begin{array}{l}\text { - Difficulty in responding to such a } \\
\text { situation when communication is } \\
\text { lost. } \\
\text { Changes in the control method of } \\
\text { the distributed generation are not } \\
\text { taken into account. }\end{array}$ \\
\hline
\end{tabular}

The remainder of this paper is organized as follows: In Section 2, various structures and control methods currently applied to remote microgrids, and the protection methods for them, are described. In Section 3, the response property is analyzed when there is a three-phase short circuit of a synchronous generator and an inverter to design an adaptive protection method. In Section 4, an adaptive protection method is proposed to solve the problems of protection methods for the remote microgrids described in Section 2. Case study and simulation results are shown in Section 5. Finally, the conclusions are presented in Section 6.

\section{Conventional Protection Coordination Method of Remote Microgrid and Its Problem}

Protection coordination is the behavior of setting the operation timing and the magnitude of the operation current of each protection relay such that a minimum area, including the fault occurrence point, can be isolated as quickly as possible when several of these protection relays are installed. The protection relay has the function of always monitoring the generator, the transformer, the bus, the line, and other components of the power grid to detect faults immediately when they occur in these components or when there is an abnormality in the operation of the grid to isolate the fault point, thereby preventing power supply disruptions and reducing damage to the machine or facilities where the fault occurs. When protection coordination is not performed appropriately, the relay that should be operated is not operated, causing damage to the system, or a relay that should not be operated is operated, thereby extending the outage area.

The remote microgrid protects the machine using a method of first operating the breaker closest to the fault point based on the differences in operation times between multiple overcurrent relays. Figure 1 shows a protection method for remote microgrids using multiple over-current relays. As shown in Figure 1, when fault (f3) occurs on the end of the line, Relay \#5 is operated first to open a breaker for the line, thus separating the fault area from the remaining grid. Even if a low voltage and a low frequency are generated in the entire grid during the fault separation time, the remaining grid can supply power 
normally after the fault area is separated. Similarly, when fault (f2) occurs, Relay \#3 is operated first, and when fault (f1) occurs, Relays \#1 and \#2 are each operated to protect the generator.

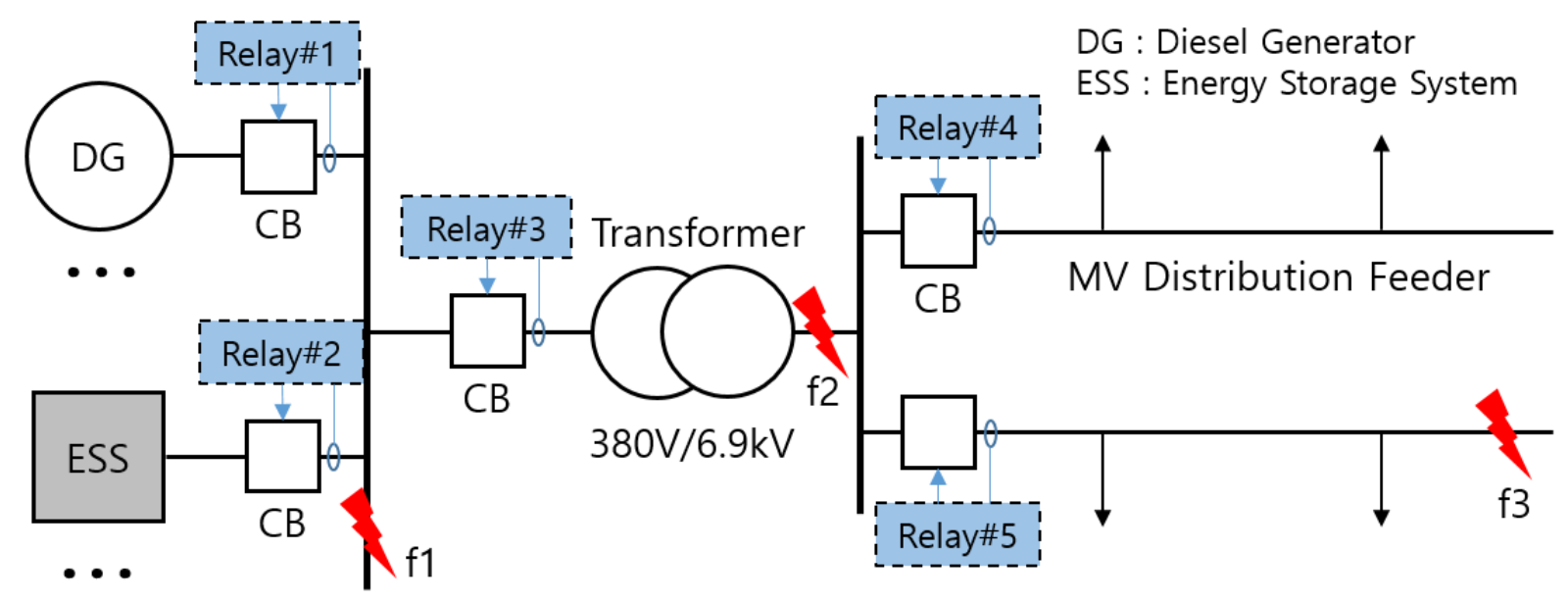

Figure 1. Several over current relay at single bus isolated microgrid.

However, such protection coordination is effective only when the generator of the remote microgrid is not changed. For example, if the fault occurs in a remote microgrid composed of only synchronous diesel generators, a relatively large fault current is supplied to the fault point. However, a relatively small fault current is generated if the remote microgrid is composed of only an inverter-based ESS and renewable energy. In other words, since the fault currents are significantly different in these two situations, the relay may not be operated accurately. This problem is worsening as the type and number of generators constituting the remote microgrid increase. Therefore, there is a need for a new method of calculating the fault current depending upon the configuration of the generator of the remote microgrid that must be capable of correcting the protection device to make it suitable for the calculated fault current.

\section{Fault Response of Inverter}

The response property for a fault in inverter-based distributed generation is very different from that for synchronous generators-it may not be calculated by applying the traditional power grid analysis [32,33]. Such a property becomes a factor in the misoperation or malfunction of the protection device for a transient period. Therefore, to secure the safety of the inverter switching element and the reliability of operation of the protection device, the response property for the line fault of the inverter should be identified. Inverters may be classified into droop control, constant voltage and constant frequency control, and active power and reactive power control. This paper considers only droop control in looking at the parallel operation of diesel generators and an ESS in an ESS islanding operation.

Droop control may be modeled by a voltage source having a series output impedance. The power loop of the droop control inverter delivers a base voltage signal to an internal control loop. A current limiter and a pulse width modulation (PWM) limiter are added to the internal control loop. Figure 2 shows a fault model of the droop control inverter. On the left is a zero-sequence equivalent circuit, and on the right is a negative sequence equivalent circuit. The Figure also confirms that the magnitude of the voltage source is determined by $V_{\text {min }}$, which is the minimum value of the droop limiter, and the simulation result thereof is shown in Figure 3. Figure 3 confirms that the droop controller limits the magnitude of the internal voltage of the inverter and each frequency to values not smaller than the thresholds [34]. 

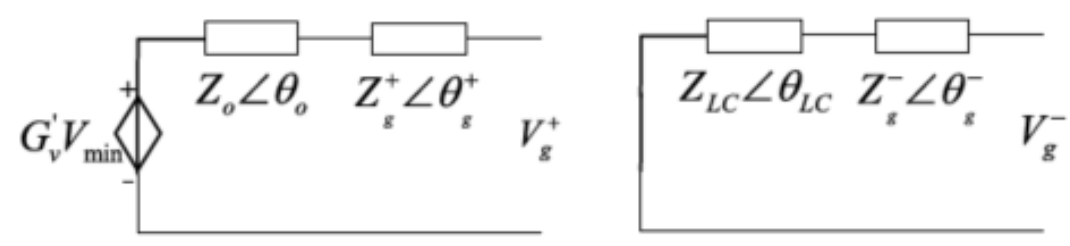

Figure 2. Positive (left) and negative (right) sequence equivalent circuits of droop-controlled inverter with droop limiters [34].
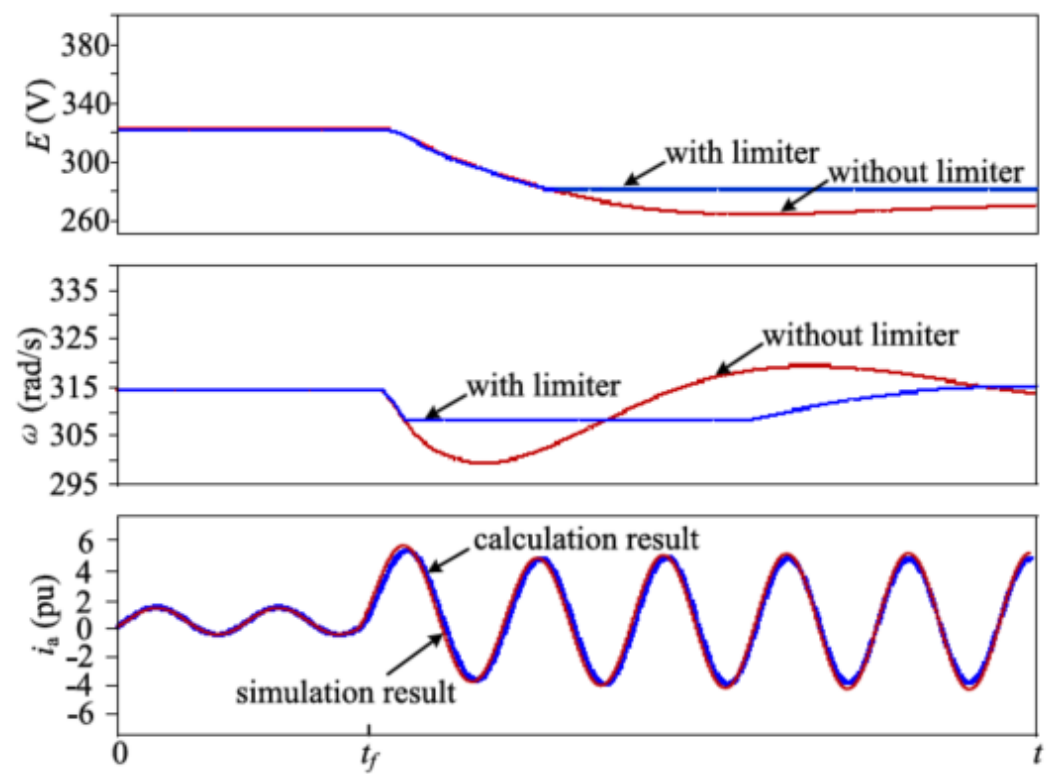

Figure 3. Magnitude of the reference voltage (upper), reference angular frequency (middle), and phase a fault current (bottom) of droop-controlled inverter with or without droop limiters when subjected to symmetrical faults at $t_{f}$ (PCC voltage dip to $70 \%$ of the rated value) [34].

\section{Adaptive Protection Method Design}

This section proposes an adaptive protection method for solving other protection method problems that occur when the fault response properties of the two generators are different and the magnitude of the fault current changes according to the combination of the generators in remote microgrids composed of diesel generators and inverters. The adaptive protection method actively changes the setting value of the protection relay according to the magnitude of the fault current, which adjusts according to the combination of generators, unlike conventional methods where the setting value of the relay (T-C curve) is set once and does not change. The proposed adaptive protection method receives information on the state of various generators, including IBRES. It transmits the T-C curve to each relay after calculating the fault current according to the combination of generators. If the ESS is being operated alone or in parallel with a diesel generator, the EMS determines whether the line has failed based on whether the current limiter of the ESS is continuously operated. After that, the EMS selects and directly controls the relay to be operated by comparing the currents of the relays.

\subsection{Adaptive Protection Method}

Figure 4 shows the entire flowchart for the adaptive protection method. Since the magnitude of the fault current changes depending upon the configuration of the generator, the adaptive protection method starts with identifying the generator in operation that is supplying power to the microgrid. Since the fault current property changes significantly depending upon whether the inverter is being operated, it is classified into the following 
cases: operation of only the diesel generator, operation of only the ESS, and parallel operation of the diesel generator and the ESS.

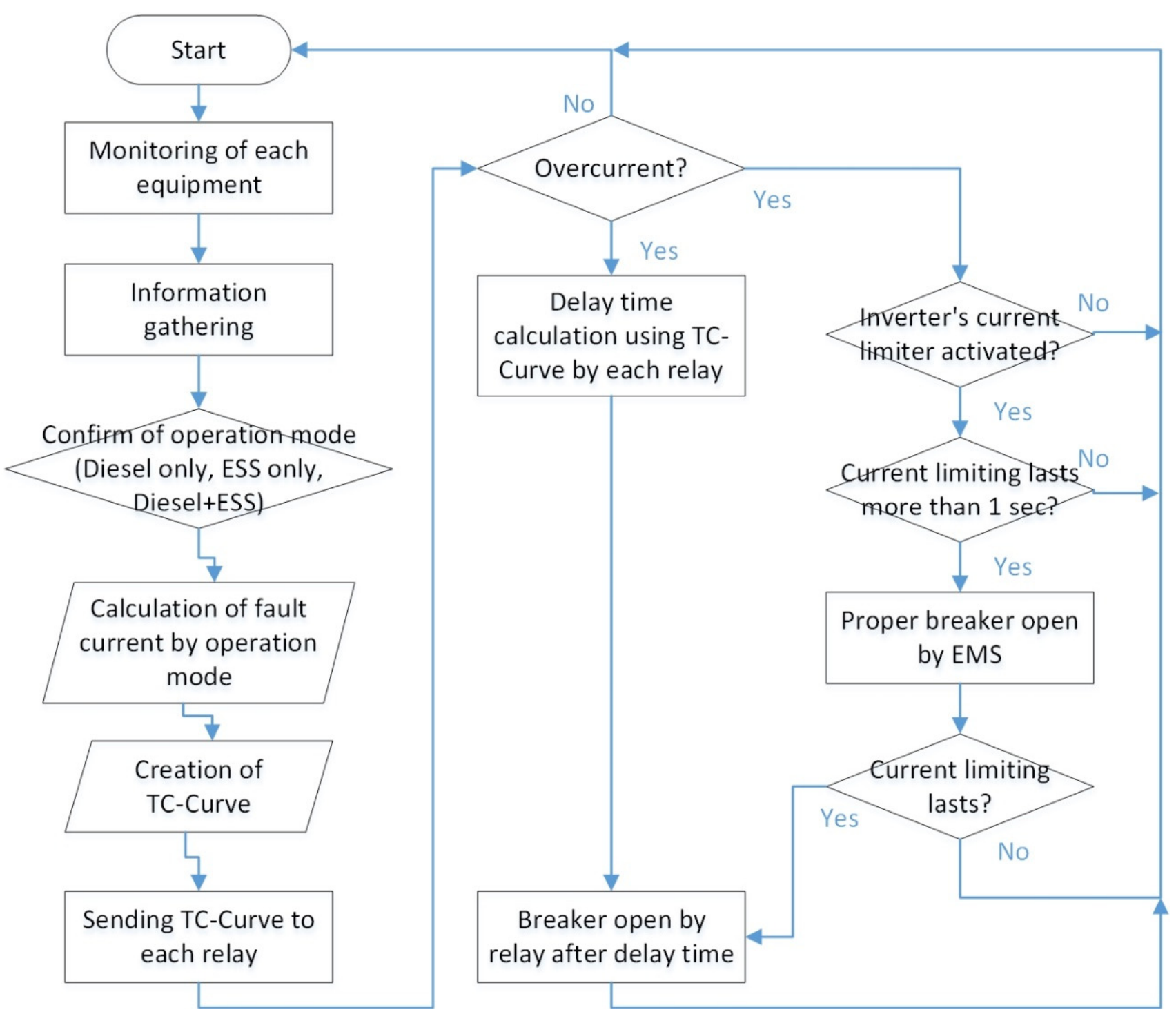

Figure 4. Overall process of adaptive protection algorithm.

Next, the fault current is calculated depending upon each operation mode. A more precise method for calculating the fault current that considers the inverter is described in Section 4.2. Next, the T-C curve for correcting the protection coordination is generated using the calculated fault current and the maximum load information of each distribution feeder. A more detailed method for generating the time-current curve is described in Section 4.3. Finally, the generated curve is transmitted to each relay. After a fault occurs, the relay that picks up the fault calculates a delay time based on the updated T-C curve. Then, the relay issues an open command to the circuit breaker that it manages when the calculated delay time elapses, and the fault area is separated. The relay where the fault is resolved (the fault current returns to the normal current) within the delay time initializes the fault pick-up.

When a fault occurs while the ESS is being operated, the ESS immediately supplies the fault current and operates the current limit function because an overcurrent is generated in the inverter. Since a fault can occur at any point in the inverter, if the current limit function and the magnitude of the fault current are similar, or if the difference between the normal 
load current and the fault current is not significant, it is difficult to isolate the fault location with only the relay effectively. Further, since the small fault current of the inverter does not cause thermal damage to the power facility, even if the fault occurs in the microgrid, it is unnecessary to handle the fault rapidly compared to when a diesel generator supplies power. However, if the fault continues, it may not be left neglected because it can harm people, animals, the inverter, etc. Therefore, if the inverter is supplying power, the fault should be handled in coordination with an upper-level control system, such as the EMS, capable of monitoring the entire microgrid and the inverter. Further, the relay should have a T-C curve for backup protection in case of communication loss between the respective machines, the misoperation of the EMS, etc. In addition, the T-C curve should, at this time, be set in consideration of the addition of a transformer to the microgrid or the generation of an inrush current, such as the inrush current of the motor. The duration of the inrush current is generally known to be within 30 cycles [35].

If a fault occurs or an overcurrent is generated in the microgrid, and therefore the current limit function of the inverter is operated, the inverter notifies the EMS of this fact. At the same time, since each relay picks up a large current more significant than the operation start-up current, it calculates the delay time by substituting the pick-up current with the T-C curve.

To select the relay to be operated for separating the fault point, the EMS compares the magnitude of the current measured by each relay immediately after receiving the information that the current limit function of the inverter has been operated and waits for $1 \mathrm{~s}$. The selection of the relay to be operated is determined based on whether each relay experiences the fault current. If one of several relays for line protection, the relay for inverter protection, and the relay for transformer protection experience the over current, it means that the fault has occurred in the line protected by the corresponding relay for line protection. Therefore, the corresponding relay for the line is selected as the relay to be operated. Following the same logic, if all relays for line protection do not experience the overcurrent and only the relay for transformer protection and the relay for inverter protection experience the over current, the relay for transformer protection is selected as the relay to be operated. Suppose all relays for line protection and the relay for transformer protection do not experience the overcurrent and only the relay for inverter protection experiences the over current. In that case, the relay for inverter protection is selected as the relay to be operated.

Once $1 \mathrm{~s}$ has passed since the release of the current limit function of the inverter, the EMS cancels the relay to be operated. At the same time, each relay is also reset. When the current limit function of the inverter is still operating even after $1 \mathrm{~s}$, it should be determined that the fault is other than the inrush current of the transformer or the motor. Therefore, the EMS transmits a command to open the breaker to the relay selected earlier. The relay confirms whether the breaker is operating normally and notifies the EMS of the opening of the breaker. In addition, the EMS sounds an alarm for the opening of the breaker to notify the operator.

If the breaker opening command is not issued to the relay due to a communication loss, EMS error, etc., each relay opens its breaker after the corresponding time has elapsed because it has already calculated the delay time according to the T-C curve.

\subsection{Fault Current Calculation}

If only the diesel generator is being operated, the fault current can be calculated using Equation (1) regarding Figure 5.

$$
I_{F-\text { Diesel }}=\frac{100 \%}{\left(X_{d 1}^{\prime \prime} / / X_{d 2}^{\prime \prime}\right)+X_{M . T r}+Z_{\text {Line }}} \times I_{\text {base }}[A]
$$




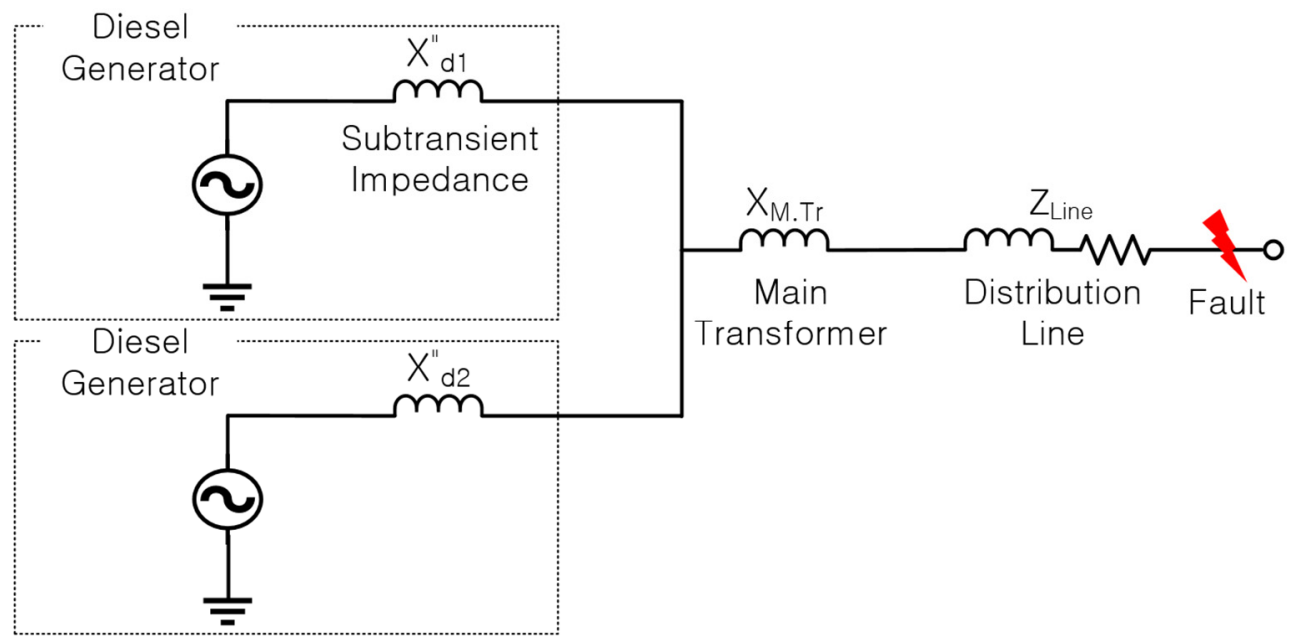

Figure 5. Equivalent circuit for fault current calculation of diesel generators.

Here, $X_{d 1}^{\prime \prime}$ and $X_{d 2}^{\prime \prime}$ refer to subtransient impedances of the diesel generator (\%), $X_{M \text {.Tr }}$ refers to the impedance of the main transformer (\%), and $Z_{\text {Line }}$ refers to the impedance of the distribution feeder (\%), and all of these values have been converted to $\%$ impedances

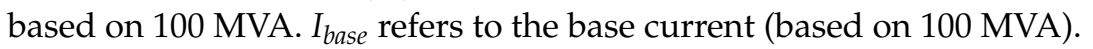

As addressed in Section 3, if a current limiter is mounted on the inverter, the fault current is determined based upon the setting value of the current limiter. Since the setting value of the current limiter may be set for the $d$ axis and the q axis, respectively, the fault current of the inverter may be calculated using Equation (2) regarding Figure 6.

$$
I_{F-\text { Inverter }}=\sqrt{I_{d l i m}^{2}+I_{q l i m}^{2}}
$$

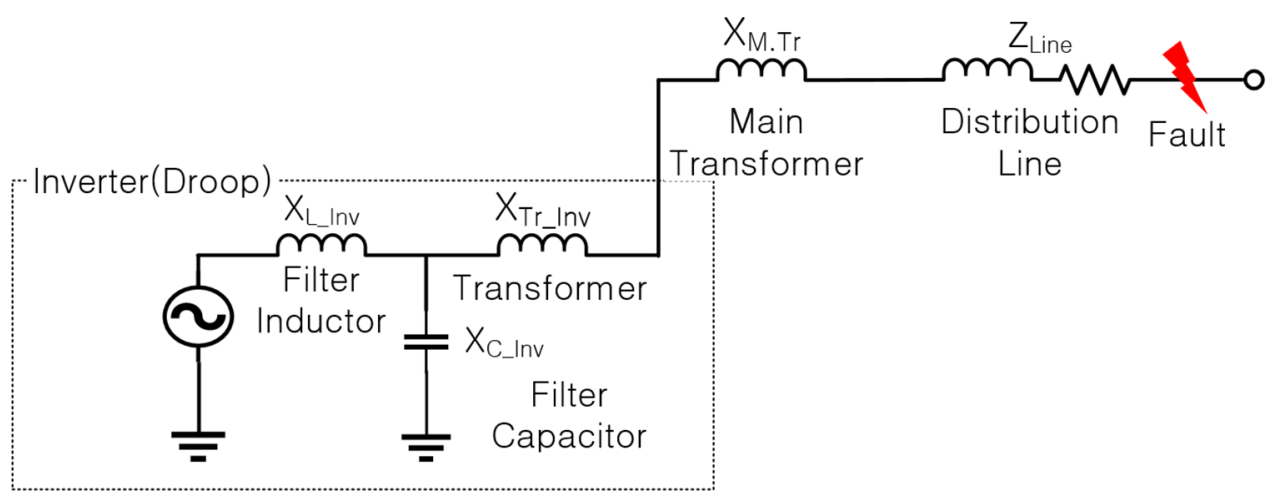

Figure 6. Equivalent circuit for fault current calculation of inverter.

Here, $I_{F-\text { Inverter }}$ refers to the fault current (RMS value) of the inverter, $I_{\text {dlim }}$ refers to the current limit value (RMS value) of the $\mathrm{d}$ axis (reactive power), and $I_{\text {qlim }}$ refers to the current limit value of the $q$ axis (active power).

If a diesel generator and inverter are operated in parallel, their fault current contribution can be calculated using the principle of superposition. If the inverter is in droop control mode, it controls the voltage across the filter capacitor. Therefore, the impedance of the filter capacitor is ignored when viewed from the diesel generator. Since the impedance $\left(X_{L I n v}\right)$ of the filter inductor of the inverter is much greater than the impedance of the distribution feeder, the fault current leaked from the diesel generator mostly flows into the 
fault point. Therefore, the impedance viewed from the diesel generator is as in Equation (3), and the fault current from the diesel generator can be calculated as in Equation (4).

$$
\begin{gathered}
\% Z_{F-\text { diesel }}=\left(X_{\text {LInv }}+X_{\text {TrInv }}\right) / /\left(X_{M . T r}+Z_{\text {Line }}\right)+X_{d}^{\prime \prime} \\
I_{F-\text { diesel-Pa }}=\frac{100 \%}{\% Z_{F-\text { diesel }}} \times I_{\text {base }}[A]
\end{gathered}
$$

When a fault occurs in the line, the inverter performs the current limit function. Therefore, Equation (2) can be used for the fault current of the inverter as it is even when the inverter is operated in parallel with a diesel generator. Therefore, the final fault current is calculated as in Equation (5) as the sum of Equations (2) and (4).

$$
I_{F-P a}=I_{F-\text { diesel-Pa }}+I_{F-\text { Inverter }}
$$

\subsection{Generation of the T-C Curve}

The T-C curve is a kind of formula for determining the relay's operation delay time. It has the property of being inversely proportional to the magnitude of the fault current picked up by the relay. Equation (5) is the T-C curve equation used by the Korea Electric Power Corporation (KEPCO), so it is used for the case studies in this paper.

$$
t=\left(\frac{39.85}{I_{M u l t i}^{1.95}-1}+1.084\right) \times \frac{L}{10}(\mathrm{~s})
$$

Here, $L$ refers to the setting value of the lever of the relay, and $I_{M u l t i}$ refers to the ratio (p.u.) of the fault current to the rated current (setting current) of the protection area.

The correction of the protection coordination isolates only the fault area from the healthy area by sequentially executing the operation time of each relay when a fault occurs. Since the operation time of the protection relay is determined by the T-C curve, in the end, the key is to set $L$ and $I_{\text {Multi }}$, which are constants of Equation (6), for each relay. A method for calculating $I_{\text {Multi }}$ and $L$ is described in Sections 4.3.1 and 4.3.2.

\subsubsection{Calculation of $I_{\text {Multi }}$}

$I_{\text {Multi }}$ is calculated according to the following procedure.

(1) First, the tap of the relay is calculated using Equation (7). At this time, 150\% is added in consideration of an overload operation of the machine, the precision of the Current Transformer (CT), etc.

$$
\text { Tap }=\frac{k W / P F}{\sqrt{3} \times k V} \times 150 \% \times \frac{I_{C T ~ s e c}}{I_{C T P r i}}
$$

Here, Tap refers to the correction value of the tap of the relay, $k W$ refers to the rated capacity of the machine, $P F$ refers to the operating power factor of the machine (applicable to only generators), $k V$ refers to the rated voltage of the machine, $I_{C T \text { Pri }}$ refers to the primary side rated current of the current transformer of the relay, and $I_{C T}$ Sec refers to the secondary side rated current of the $\mathrm{CT}$ of the relay.

(2) The \% impedance (sub transient impedance is applied to the generator) of the machine is converted into the base capacity (here, $100 \mathrm{MVA}$ ).

$$
\% Z_{100 \mathrm{MVA}}=\frac{100 \mathrm{MVA} \times \% \mathrm{Z}}{k W / P F}[\%]
$$

Here, $\% Z_{100 \mathrm{MVA}}$ refers to the $\%$ impedance of the machine based on $100 \mathrm{MVA}$, and $\% Z$ refers to the $\%$ impedance based on the machine's rated capacity.

(3) The greatest possible fault current (three-phase short circuit current) is calculated using Equations (1) to (5). 
(4) Finally, $I_{M u l t i}$ (the ratio of the fault current to the rated current of the protection area) is calculated.

$$
I_{\text {Multi }}=\frac{I_{\text {fault }} \times \frac{I_{C T \text { sec }}}{I_{C T P r i}}}{\operatorname{Tap}}
$$

Here, Tap is the result to be calculated in Equation (7).

\subsubsection{Calculation of the Lever Value}

The lever value is calculated by substituting the calculated result of Equation (9) into Equation (10). At this time, the lever value is set to separate the fault based on 30 cycles such that, if possible, the machine experiencing the fault current is not damaged, assuming a three-phase short circuit fault.

$$
L=\frac{10}{\frac{39.85}{I_{\text {Multi }}^{1.95}-1}+1.084} \times \frac{30}{60}
$$

Here, 30/60 means $0.5 \mathrm{~s}$ (30 cycles).

\subsection{Setting of the Protection Relay}

The protection relay is set using Equations (9) and (10). At this time, the lever value of the relay for line protection is corrected to 0.2 , which is the minimum value to be quickly operated assuming that there is no potential machine on protection (installed on the center of the line). The lever value of the relay for transformer protection is corrected to the median of the lever values of the relay for line protection and the relay for the generator because the transformer impedance is much smaller than that of the diesel generator. Therefore, the current difference between the primary and secondary sides of the transformer is insignificant.

\section{Case Study and Simulation Results}

This chapter calculates the fault current and corrects the protection relay for a remote microgrid composed of a diesel generator with a droop function, a droop-controlled ESS inverter with a current limit function, the main transformer, a protection relay, a distribution feeder, and a load to verify the effectiveness of the adaptive protection method proposed in this paper. The modeling was performed using PSCAD/EMTDC, and the simulation result was analyzed to verify the feasibility of the corrected result.

\subsection{Target System for Verifying Performance}

The calculation of the fault current and the simulation were carried out for a remote microgrid that supplies power to an actual island area to verify the proposed method. On the generator bus, two diesel generators and two ESSs were interconnected in parallel. Both the diesel generator and the ESS were droop-controlled for parallel operation.

A relay and a breaker were installed to protect each generator, as well as the transformer. The low voltage bus was assumed to be connected to the medium voltage bus through the transformer for boost $(380 \mathrm{~V} / 6.9 \mathrm{kV})$ and the medium voltage bus assumedly had two distribution feeders. A relay and a breaker were installed on each distribution feeder to disseminate the fault to other lines when a fault occurred in the line. This is shown in Figure 7. In this paper, all relays are only for the over-current relay.

The diesel generator and the ESS can be operated in various combinations depending upon their on/off states, and in this paper, three case studies were conducted as in Table 2. The fault occurred at the end of distribution feeder \#1 (the fault is marked) to observe the coordination result between the protection device, and the fault type was a three-phase short circuit. Table 2 shows the specifications of the current transformer (CT) and the combination of the generator and load for each case. 


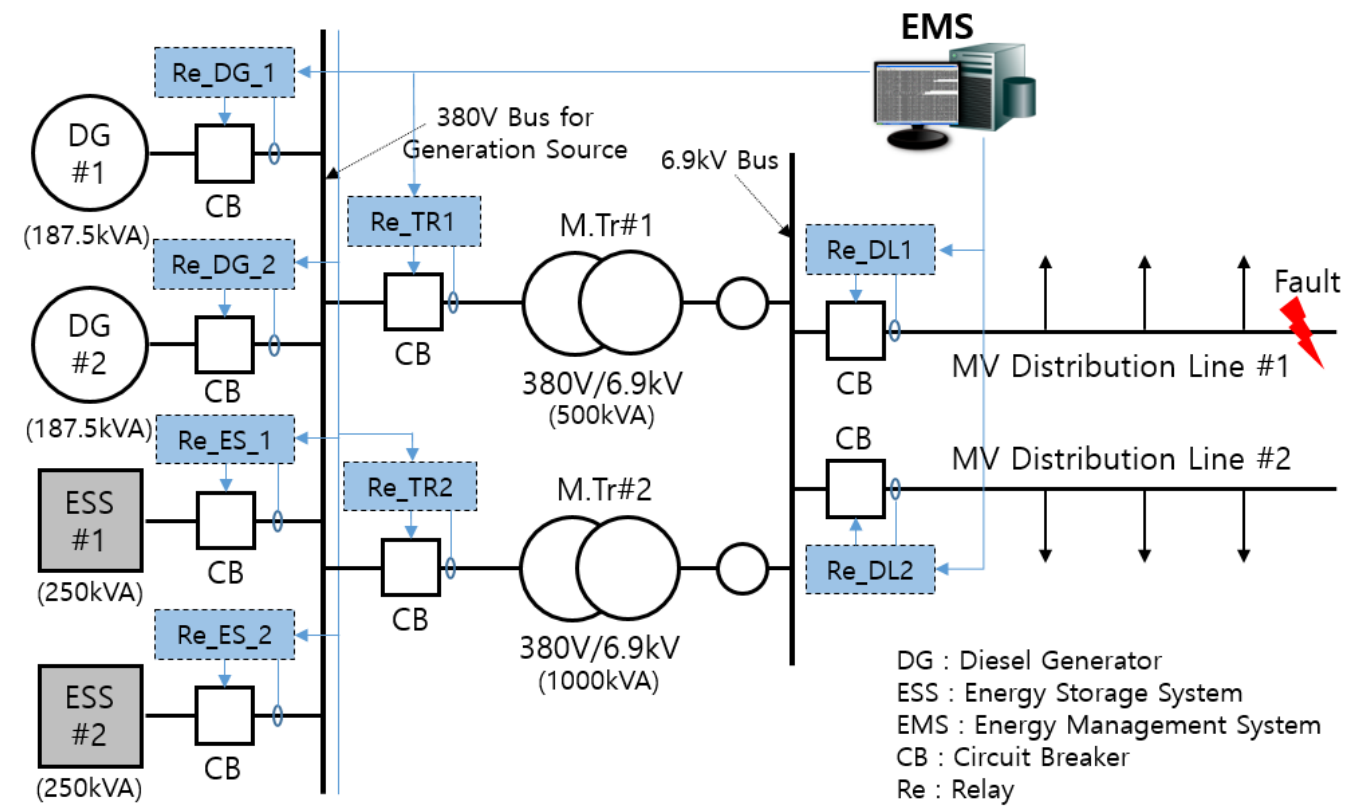

Figure 7. Single line diagram for adaptive protection scheme design of isolated microgrid.

Table 2. Parallel operation combination of diesel generators and ESSs.

\begin{tabular}{|c|c|c|c|c|c|c|c|c|c|}
\hline \multirow{2}{*}{ Case } & \multirow{2}{*}{$\begin{array}{l}\text { Diesel } \\
\text { Gen.\#1 }\end{array}$} & \multirow{2}{*}{$\begin{array}{l}\text { Diesel } \\
\text { Gen.\#2 }\end{array}$} & \multirow{2}{*}{$\begin{array}{c}\text { ESS } \\
\# 1\end{array}$} & \multirow{2}{*}{$\begin{array}{c}\text { ESS } \\
\# 2\end{array}$} & \multirow{2}{*}{$\begin{array}{c}\text { Main Transformer } \\
\text { (kVA) }\end{array}$} & \multicolumn{2}{|c|}{ Maximum Load (kW) } & \multicolumn{2}{|c|}{ Supply Load (kW) } \\
\hline & & & & & & Line1 & Line2 & Line1 & Line2 \\
\hline $\begin{array}{c}\text { CT } \\
\text { Ratio }\end{array}$ & $400: 5$ & $400: 5$ & $600: 5$ & $600: 5$ & $\begin{array}{l}\text { 1000:5 } \\
\text { 2500:5 }\end{array}$ & $200: 5$ & $200: 5$ & $200: 5$ & $200: 5$ \\
\hline \#1 & Droop & Droop & off & off & 500 & 200 & 120 & 150 & 90 \\
\hline$\# 2$ & off & off & Droop & Droop & 500 & 300 & 200 & 210 & 150 \\
\hline$\# 3$ & Droop & Droop & Droop & Droop & 1000 & 500 & 300 & 390 & 210 \\
\hline
\end{tabular}

\subsection{Fault Current Calculation}

To correct the setting value of the protection relay, the fault currents of each generator and that at the fault point should be calculated assuming that the fault occurs in the corresponding protection area of the relay. The impedances of the power generation source and the main machines for calculating the fault current are shown in Table 3 [36].

Table 3. \% Impedance of generation sources and pieces of equipment [36].

\begin{tabular}{|c|c|c|c|}
\hline \multicolumn{2}{|c|}{ Equipment } & \multirow{2}{*}{$\begin{array}{c}\text { Original Value } \\
10.72 \%\end{array}$} & \multirow{2}{*}{$\begin{array}{c}\begin{array}{c}\text { \%Impedance } \\
\text { (at } 100 \text { MVA) }\end{array} \\
5732.6 \%\end{array}$} \\
\hline $\begin{array}{l}\text { Diesel Generator } \\
(187.5 \mathrm{kVA})\end{array}$ & $\begin{array}{l}\text { Subtransient } \\
\text { Impedance }\left(X_{d}^{\prime \prime}\right)\end{array}$ & & \\
\hline \multirow{2}{*}{$\begin{array}{l}\text { Inverter } \\
(250 \mathrm{kVA})\end{array}$} & $\begin{array}{l}L \text { Filter }\left(X_{L \_I n v}\right) \\
\text { C Filter }\left(X_{C}=\right.\end{array}$ & $\begin{array}{l}0.1 \mathrm{mH} \\
160 \mathrm{uF}\end{array}$ & $\begin{array}{c}3681.6 \% \\
-1619.007 .8 \%\end{array}$ \\
\hline & $\begin{array}{c}\text { Transformer }\left(X_{\text {Tr_Inv }}\right) \\
(275 \mathrm{kVA})\end{array}$ & $4.75 \%$ & $1727.3 \%$ \\
\hline $\begin{array}{l}\text { Main Transformer } \\
\text { (500 kVA) }\end{array}$ & Impedance $\left(X_{M . T r}\right)$ & $4.6 \%$ & $920.0 \%$ \\
\hline $\begin{array}{l}\text { Main Transformer } \\
(1000 \mathrm{kVA})\end{array}$ & Impedance $\left(X_{M . T r}\right)$ & $5.1 \%$ & $510.0 \%$ \\
\hline $\begin{array}{c}\text { Distribution Line } \\
\left(\text { ACSR95 } \mathrm{mm}^{2}, 5 \mathrm{~km}\right)\end{array}$ & Impedance $\left(X_{\text {Line }}\right)$ & $2.48+j 2.19$ & $694.9 \%$ \\
\hline
\end{tabular}


The results of calculating the fault current using Equations (1) to (5) derived in Section 4.2 are shown in Table 4 . The relay cannot be accurately operated with its fixed setting value because the difference in the fault current can be up to 3.3 times depending upon the configuration of the generator. Such a misoperation can worsen when there is more variation in the configuration of the generator.

Table 4. Summary of fault current calculation by case.

\begin{tabular}{cccc}
\hline \multirow{2}{*}{ Case } & \multicolumn{2}{c}{ Fault Current of Generation Sources [A] } & \multirow{2}{*}{ Fault Current at Relay of DL1 [A] } \\
\cline { 2 - 3 } & Diesel & Inverter & \\
\hline$\# 1$ & 2650.3 & - & 186.7 \\
$\# 2$ & - & 569.8 & 62.8 \\
$\# 3$ & 2650.3 & 569.8 & 278.6 \\
\hline Voltage & at $380[\mathrm{~V}]$ & at 380 [V] & at $6.9[\mathrm{kV}]$ \\
\hline
\end{tabular}

\subsection{Protection Coordination among Relays}

In this section, the $\mathrm{T}-\mathrm{C}$ curve is generated using the result from calculating the fault current in Section 5.2, the generation of the T-C curve in Section 4.3, and the method for setting the protection relay in Section 4.4. The T-C curve generated is transmitted to each relay. Each relay monitors the current and starts operation when picking up a current equal to or greater than the operation start-up current of the relay. The tap values and the lever values corrected for each case are summarized in Tables 5 and 6 . The CT ratio and the maximum load for calculating the tap and lever value are shown in Table 2.

Table 5. Coordination results of lever (delay) for isolated microgrid.

\begin{tabular}{ccccccc}
\hline Case & $\begin{array}{c}\text { Diesel } \\
\text { Generator }\end{array}$ & ESS & $\begin{array}{c}\text { Transformer } \\
\mathbf{5 0 0} \mathbf{k V A})\end{array}$ & $\begin{array}{c}\text { Transformer } \\
\mathbf{( 1 0 0 0} \mathbf{k V A})\end{array}$ & Line \#1 & Line \#2 \\
\hline$\# 1$ & 2.2 & - & 1.2 & - & 0.2 & 0.2 \\
$\# 2$ & - & 1.5 & 1.0 & - & 1.2 & 1.2 \\
$\# 3$ & 2.2 & 0.7 & - & 0.4 & 0.2 & 0.2 \\
\hline
\end{tabular}

Table 6. Coordination results of Tap (pick-up current) for isolated microgrid.

\begin{tabular}{ccccccc}
\hline Case & $\begin{array}{c}\text { Diesel } \\
\text { Generator }\end{array}$ & ESS & $\begin{array}{c}\text { Transformer } \\
\mathbf{5 0 0} \mathbf{~ k V A})\end{array}$ & $\begin{array}{c}\text { Transformer } \\
\mathbf{( 1 0 0 0} \mathbf{~ k V A})\end{array}$ & Line \#1 & Line \#2 \\
\hline \multirow{2}{*}{$\# 1$} & $426.2 \mathrm{~A}$ & - & $1139.5 \mathrm{~A}$ & & $25.1 \mathrm{~A}$ & $15.1 \mathrm{~A}$ \\
& $(5.3)$ & & $(5.7)$ & - & $(0.6)$ & $(0.4)$ \\
$\# 2$ & - & $398.8 \mathrm{~A}$ & $835.6 \mathrm{~A}$ & - & $37.6 \mathrm{~A}$ & $25.1 \mathrm{~A}$ \\
& & $(3.3)$ & $(4.2)$ & & $(0.9)$ & $(0.6)$ \\
$\# 3$ & $426.2 \mathrm{~A}$ & $398.8 \mathrm{~A}$ & - & $1823.2 \mathrm{~A}$ & $62.8 \mathrm{~A}$ & $37.7 \mathrm{~A}$ \\
& $(5.3)$ & $(3.3)$ & & $(3.6)$ & $(1.6)$ & $(0.9)$ \\
\hline
\end{tabular}

Since the lever value indicates a time delay that is inversely proportional to the magnitude of the fault current generated, the same value is shown for each case except where only the ESS is operated. On the other hand, since the tap value is the threshold that picks up the current measured in the relay as the fault, it varies depending upon the rated capacity and the maximum load of the machine. As described above, for a remote microgrid, the fixed correction value of the relay cannot protect the microgrid because the setting value of the relay changes depending upon the combination of the generator.

Figures 8 and 9 show the generation of T-C curves for Cases \#1 and \#2 using the results in Tables 5 and 6, respectively. A T-C curve can also be similarly generated in Case \#3, therefore omitting it. 


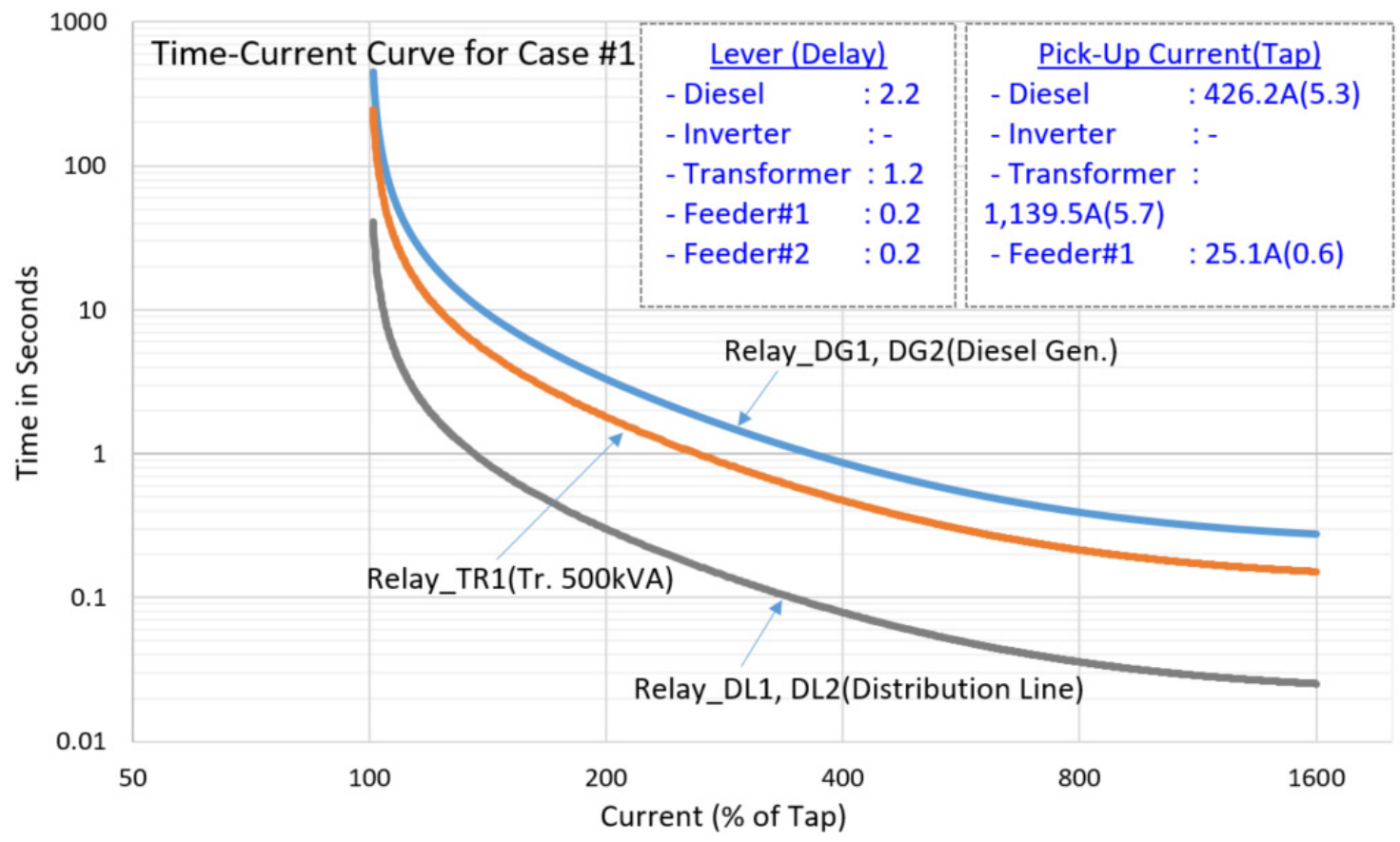

Figure 8. T-C curve for case \#1 (diesel gen. only).

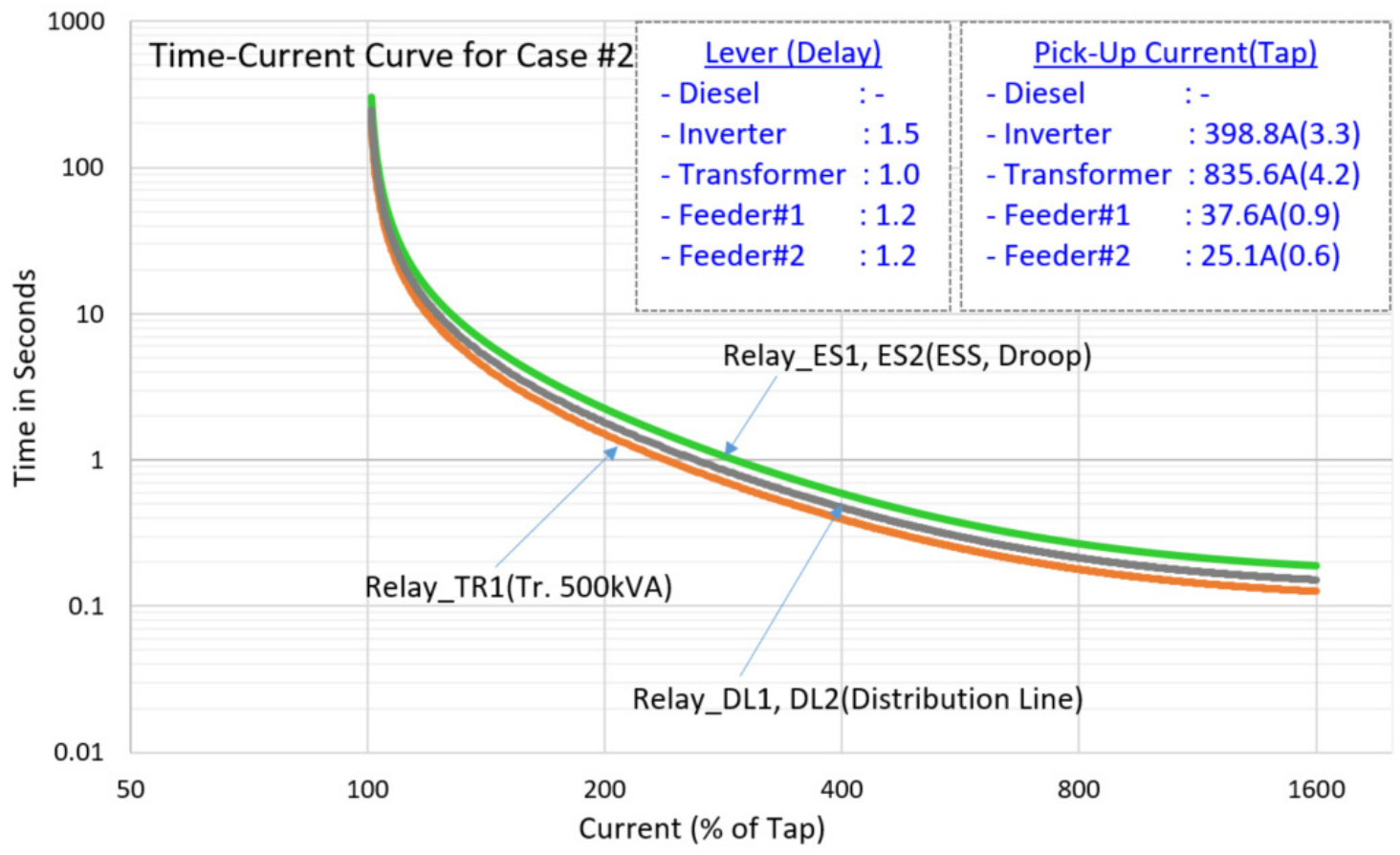

Figure 9. T-C curve for case \#2 (ESS only).

\subsection{Simulation Results}

The simulation for Figure 7 was conducted using PSCAD/EMTDC to verify the feasibility of the adaptive protection method. First, whether each relay was normally operated by creating a three-phase short circuit fault at the end of the distribution feeder was confirmed. To this end, the simulation was started and caused a fault after the controllers of the diesel generator and the ESS were stabilized. Then, each relay could either pick up or not pick up the fault, depending upon the fault location and trip the breaker after a certain time delay depending upon a predetermined T-C curve when picking up the fault. 


\subsubsection{Case \#1}

Case \#1 is a case of fault handling for a three-phase short circuit that occurs while a load of $240 \mathrm{~kW}$ is supplied during the operation of a diesel generator under droop control. The simulation results for Case \#1 are shown in Figure 10. Figure 10a shows the waves of the fault current of the diesel generator, Figure 10b shows the current (RMS) of phase A for each relay, and Figure $10 \mathrm{c}$ shows the trip signal (' 0 ' refers to closing, ' 1 ' refers to opening) for the breaker of each relay. The fault occurred $10 \mathrm{~s}$ after the simulation started.

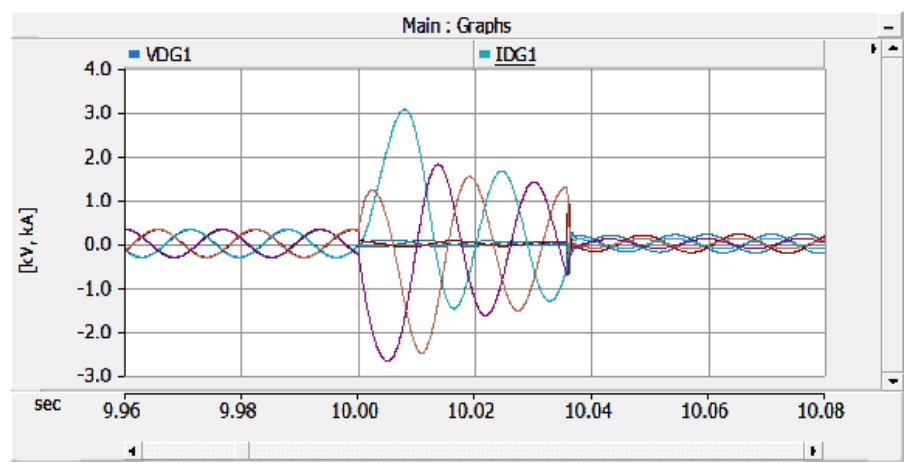

(a)

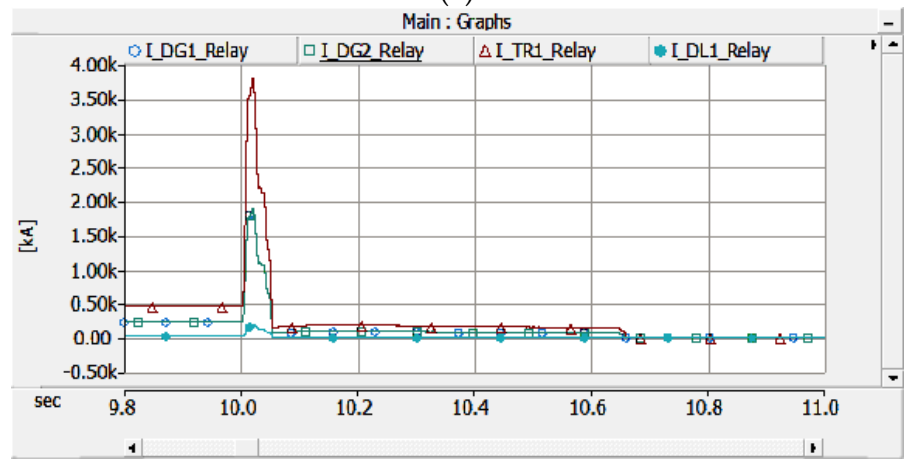

(b)

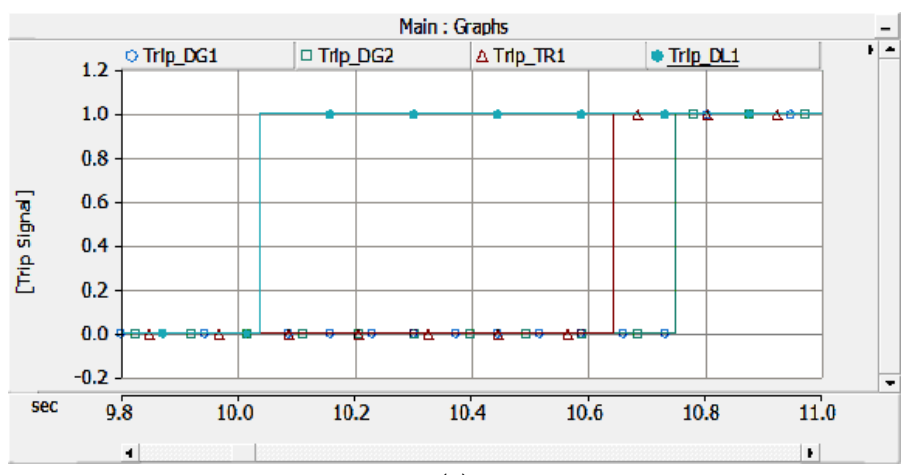

(c)

Figure 10. Simulation results of Case \#1: (a) voltage and current of diesel generator \#1; (b) current of each relay; (c) trip signal of each relay.

The fault current (I_DL1_Relay) experienced by the relay for the line was $188.7 \mathrm{~A}$ (based on $6.9 \mathrm{kV}$ ), almost the same as $186.7 \mathrm{~A}$, which is the calculated result of Table 4 . The relay for the line generated the trip signal for the breaker at $0.034 \mathrm{~s}$ after the fault occurred, which is almost the same as the result of $0.036 \mathrm{~s}$, calculated using Figure 8. Further, the operation time of the relay for the transformer in the simulation was $0.639 \mathrm{~s}$, almost the same as the result of $0.641 \mathrm{~s}$, the calculated result using Figure 8. Likewise, the trip signal of the relay for the diesel generator was generated at $0.745 \mathrm{~s}$ after the fault occurred, which almost coincides with the calculated result of 0.747 . 


\subsubsection{Case \#2}

Case \#2 is a case of fault handling for a three-phase short circuit that occurs while a total load of $360 \mathrm{~kW}$ is supplied during the operation of two ESSs under droop control. The simulation results are shown in Figure 11. The relay for Line \#1 experienced a fault current of $61.4 \mathrm{~A}$, almost the same as $62.8 \mathrm{~A}$, calculated based on Table 4. According to the T-C curve, the relay for Line \#1 should be operated at $2.898 \mathrm{~s}$. However, since the EMS issued the trip command $1.1 \mathrm{~s}$ (11.1 s in the graph) after the fault occurred, the breaker of Line \#1 was opened, and the fault area was separated from the microgrid. In Figure 11b, the fault was removed at $11.1 \mathrm{~s}$, and therefore, the load was normally supplied to Line \#2. The T-C curve of the relay was set using the backup protection method in preparation for a case where the EMS could not handle the fault. Figure 11c shows the operation time of another relay if the fault continues (assuming the non-operation of the relay for the distribution feeder). It can be confirmed that the relay for the transformer was operated at $4.852 \mathrm{~s}$, and the relay for the ESS was operated at $6.053 \mathrm{~s}$, respectively.

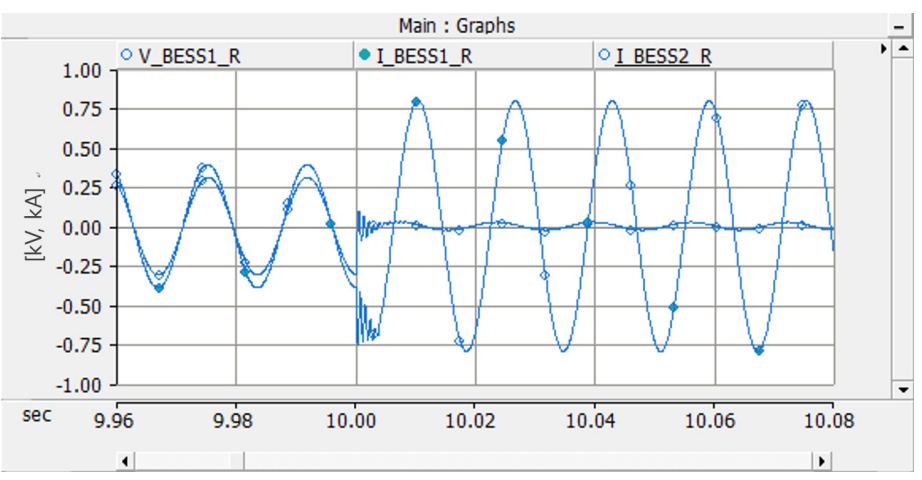

(a)

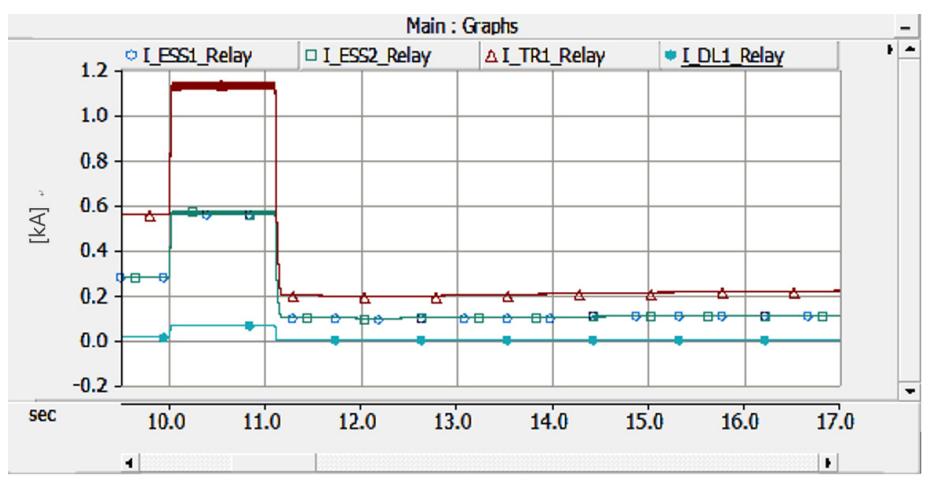

(b)

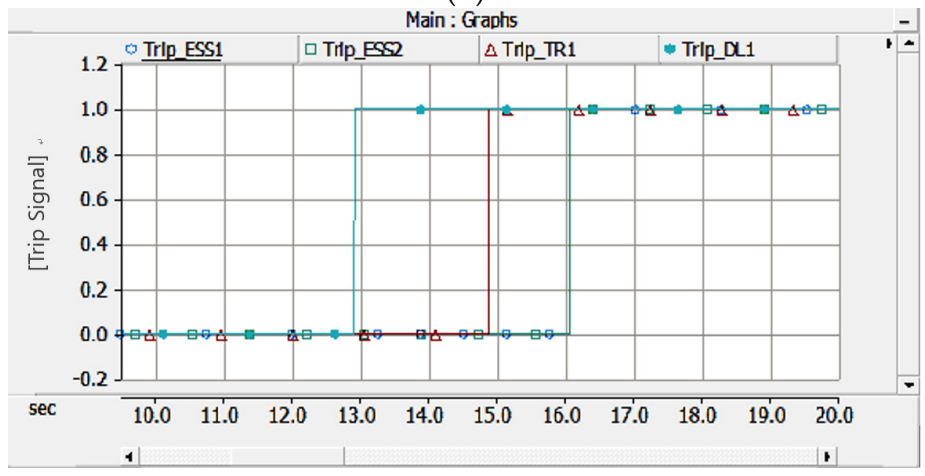

(c)

Figure 11. Simulation results of Case \#2: (a) voltage and current of ESS\#1 and \#2; (b) current of each relay; (c) trip signal of each relay. 


\subsubsection{Case \#3}

Case \#3 is where a three-phase short circuit fault occurs while a load of $600 \mathrm{~kW}$ is supplied to two diesel generators and two ESSs. The simulation results for Case \#3 are shown in Figure 12. The fault current (I_DL1_Relay) experienced by the relay for the line was $280.4 \mathrm{~A}$, which is almost the same as $278.6 \mathrm{~A}$, the calculated result of Table 4 . The relay for Line \#1 generated the trip signal of the breaker at $0.064 \mathrm{~s}$ after the fault occurred, which almost coincides with the calculated result using Tables 5 and 6. In Figure 12b, it can be confirmed that the breaker for Line \#1 was opened at $20.064 \mathrm{~s}$, and then normal power was continuously supplied to Line \#2 until the relay for the transformer was opened at $20.251 \mathrm{~s}$. In Figure 12c, it can be confirmed that the relay for the line, the relay for the transformer, the relay for the diesel generator, and the relay for the ESS generate the trip signals sequentially, as designed.

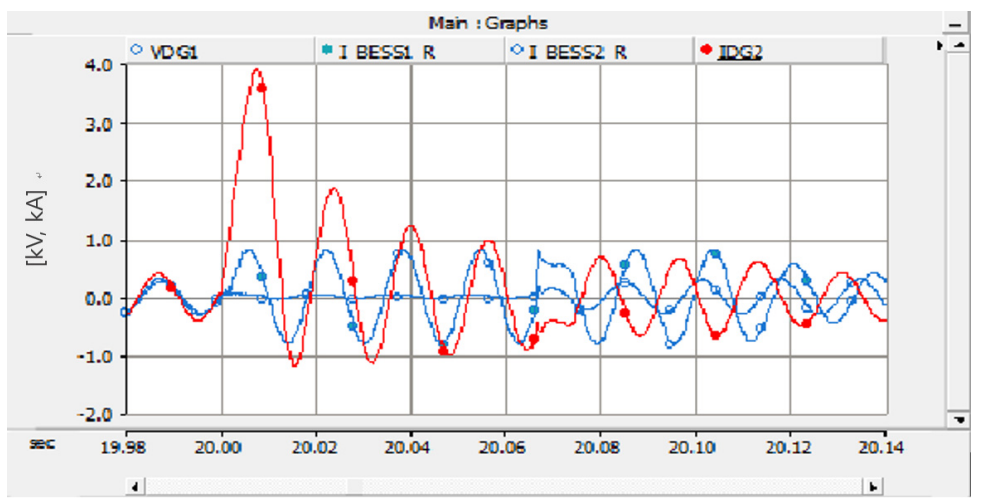

(a)

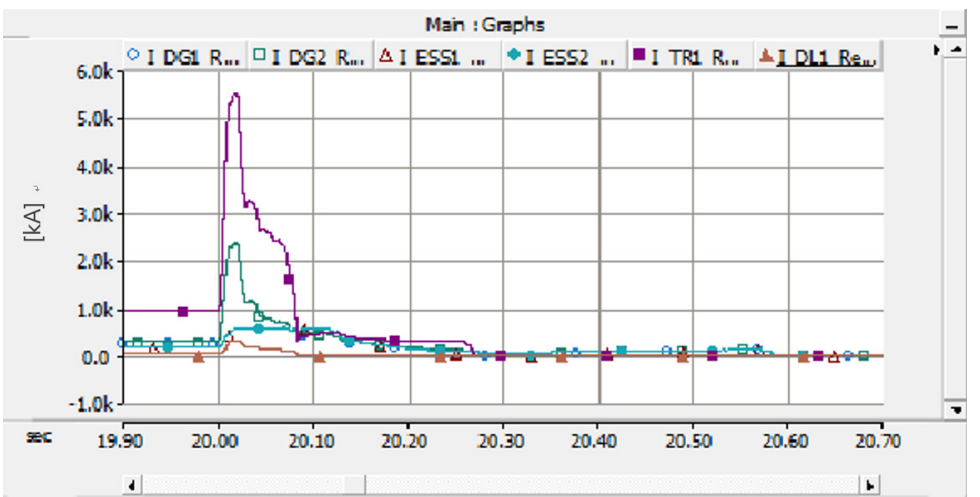

(b)

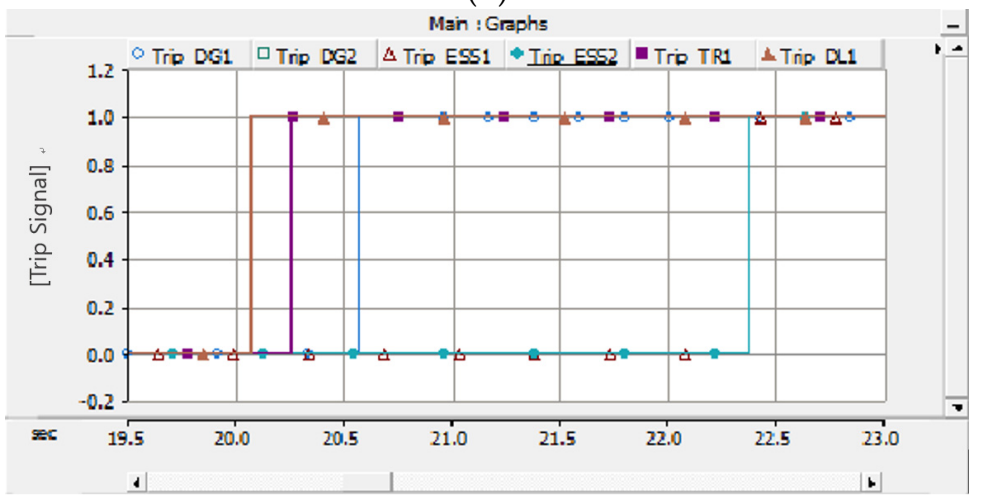

(c)

Figure 12. Simulation results of Case \#4: (a) voltage and current of diesel generators and ESSs; (b) current of each relay; (c) trip signal of each relay. 


\subsection{Consideration of the Case Studies}

The simulation was conducted in a model grid by applying the adaptive protection method of the remote microgrid proposed in Chapter 4. The simulation results confirmed that relays that corrected the T-C curve using the adaptive protection method normally perform only the operation necessary for each fault type to isolate the fault area effectively.

Case \#1 simulates the typical power supply method of island areas with only a diesel generator. Since this is the situation where the ESS was not operated, the protection relay between the respective facilities could be corrected using the typical method. Case \#2 is a case of supplying power using only the ESS, and the fault current of the ESS was 1.2 to 1.5 times the rated current. Figure 9 confirms that it is difficult to obtain the operation time difference between the relays because the T-C curve of each relay is in close contact. Further, even in Figure 11, when the EMS did not intervene in the handling of the fault, the fault continued for up to $6 \mathrm{~s}$, thereby causing danger to the safety of humans and animals, damage to the ESS, etc.

Furthermore, when the relay was set similarly to the synchronous generator without considering the fault current property of the ESS, as shown in Figure 13, the relay was not appropriately operated. Figure 13 shows the operation time of each relay in the case of applying the settings of the relays of Case \#1 to Case \#2 for the simulation. It can be confirmed that the relay for the transformer (operated at $7.00 \mathrm{~s}$ ) was operated before the relay for the ESS (operated at $10.05 \mathrm{~s}$ ). Therefore, it was not to correct the protection coordination.

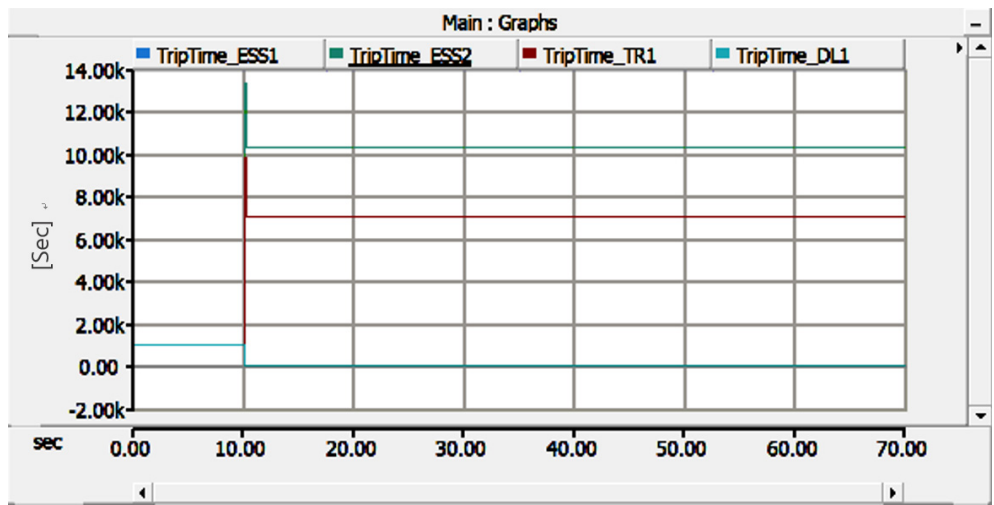

Figure 13. Relay trip time of case \#2 using relay setting of case \#1.

Table 7 shows the calculation and simulation results of the three cases, which almost coincide with each other. For the simulation results, it can be confirmed that the fault current changes from a maximum of $280.4 \mathrm{~A}$ to a minimum of $61.4 \mathrm{~A}$, depending upon the combination of the diesel generator and the ESS. This means that it is impossible to adequately respond to the magnitude of the change in fault current according to the combination of each generator and to effectively isolate the fault area only by setting the relay in one way, as has been the case in the past. This means that the outrage area can be extended due to the misoperation of the protection device. Such a change in the fault current will worsen when REC, such as a photovoltaic or wind turbine generator, is interconnected to the remote microgrid.

Table 7. Summary of fault current calculation and simulation.

\begin{tabular}{ccccc}
\hline \multirow{2}{*}{ Case } & $\begin{array}{c}\text { Number of } \\
\text { Diesel }\end{array}$ & Number of ESSs & \multicolumn{2}{c}{ Fault Current [A] } \\
\cline { 4 - 5 } Generators & 2 & 0 & 186.7 & Calculation \\
$\# 1$ & 0 & 2 & 62.8 & 188.7 \\
$\# 2$ & 2 & 2 & 278.6 & 61.4 \\
$\# 3$ & & & 280.4 \\
\hline
\end{tabular}




\section{Conclusions}

This paper proposed an adaptive protection method for solving protection problems for remote microgrids composed of diesel generators and inverter-based ESSs with different fault response properties. The adaptive protection method is a method in which the EMS identifies the change in the configuration of the generators in operation to calculate the fault current for each main point, sets the T-C curve of each protection relay using this result, and isolates the fault area as each relay is operated depending upon the T-C curve if a fault occurs. At this point, the paper proposed a method by which the EMS confirms whether the current limiter of the inverter has been operated when it is difficult for the inverter to distinguish the load current from the fault current to operate the protection relay directly.

A remote microgrid composed of a diesel generator, an inverter, the main transformer, a distribution feeder, a load, relays, and a breaker using the PSCAD/EMTDC was used to verify the effectiveness of the proposed adaptive protection method. Three simulations were conducted to determine whether each relay and the EMS were operated normally to remove the fault in the case of a three-phase short circuit occurring at the end of the distribution feeder, with the diesel generator and the inverter-based ESS operating in three different combinations.

The simulation results confirmed that the relays were operated normally at all fault points in cases where the fault occurred in the line when the adaptive protection method was applied. In Case \#1, only the diesel generator was operated, and the fault could be handled using the typical protection method. In Case \#2, only the inverter-based ESS was operated. The magnitude of the fault current was about 30\% compared to that of Case \#1, the fault could not be removed using the relay settings of Case \#1, and the fault could only be removed when the EMS intervened using the method proposed in this paper. In Case $\# 3$, the diesel generator and the droop control inverter were operated in parallel. It was confirmed that the relay for the protection of the diesel generator could be operated in coordination with other relays, and the inverter could be operated normally only when the EMS intervened.

This paper proves through simulation that the relay does not operate normally when only the diesel generator is in operation with the protection coordination result, which is set for the inverter only. In addition, it was confirmed that if a failure occurs when only the inverter is in operation, the separation of the faulty section is delayed unless EMS intervenes. In addition, according to the change of distributed generation, it is possible to solve problems such as communication interruption and communication delay, which are the disadvantages of the previously proposed method to protect the microgrid by communication only. Therefore, it was confirmed that the proposed method can effectively protect remote microgrids composed of various types of distributed generation.

The proposed protection method may be applied when IBRES and ESSs are interconnected to remote microgrids using only a diesel generator in the future. Further, it was determined that a fault current could also be applied to a power system, where the fault current significantly varies depending upon the configuration of the generator. It was also determined that since the entire fault current could vary if various types of distributed generation were interconnected with the remote microgrid, additional research would be needed into such a situation.

Author Contributions: Resources, J.-O.K.; validation, W.-H.K., S.H. and J.-H.L.; writing-original draft preparation, W.C.; writing — review and editing, J.-E.K. All authors have read and agreed to the published version of the manuscript.

Funding: This research received no external funding.

Institutional Review Board Statement: Not applicable.

Informed Consent Statement: Not applicable.

Conflicts of Interest: The authors declare no conflict of interest. 


\section{References}

1. Lasseter, R.H. Microgrids. In Proceedings of the IEEE Winter Meeting Power Engineering Society, New York City, NY, USA, 27-31 January 2002; pp. 305-308.

2. IEC Technical Specification. IEC TS 62898-1 Guidelines for Microgrid Projects Planning and Specification; IEC: Geneva, Switzerland, 2017.

3. Martínez-Cid, R.; O'Neill-Carrillo, E. Sustainable Microgrids for Isolated Systems. In Proceedings of the IEEE PES Transmission and Distribution Conference and Exposition, New Orleans, LA, USA, 19-22 April 2010; pp. 1-7.

4. Green, T.C.; Prodanovic, M. Control of Inverter-Based Micro-Grids. Electr. Power Syst. Res. 2007, $1204-1213$.

5. Nikkhajoei, H.; Lasseter, R.H. Microgrid Protection. In Proceedings of the IEEE PES General Meeting, Tampa, FL, USA, 24-28 June 2007; pp. 1-6.

6. SMA. Grid Forming Inverter Technical Memo; SMA: Niestetal, Germany, 2020.

7. Buigues, G.; Dysko, A.; Valverde, V.; Zamora, I.; Fermandez, E. Microgrid Protection: Technical Challenges and Existing Techniques. In Proceedings of the International Conference on Renewable Energies and Power Quality, Bilbao, Spain, 20-22 March 2013; pp. 222-227.

8. Beheshtaein, S.; Cuzner, R.; Savaghebi, M.; Guerrero, J. A Review on Microgrids Protection. IET Gener. Transm. Distrib. 2019, 13, 743-759.

9. Gkountaras, A.; Sezi, T. Development of a Short Circuit Strategy for Medium Voltage Hybrid Microgrids. In Proceedings of the IEEE 6th International Symposium on Power Electronics for Distributed Generation Systems (PEDG), Aachen, Germany, 22-25 June 2015.

10. Jin, D.G.; Choi, J.C.; Won, D.J.; Lee, H.J.; Chae, W.K.; Park, J.S. A practical protection coordination strategy applied to secondary and facility microgrids. Energies 2012, 5, 3248-3265.

11. Mahat, P.; Chen, Z.; Bak-Jensen, B.; Bak, C.L. A simple adaptive overcurrent protection of distribution systems with distributed generation. IEEE Trans. Smart Grid 2011, 2, 428-437. [CrossRef]

12. Oudalov, A. New Technologies for Microgrid Protection. In Symposium on Microgrids; ABB: Zurich, Switzerland, 2013.

13. Ustun, T.S.; Ozansoy, C.; Zayegh, A. A Microgrid Protection System with Central Protection Unit and Extensive Communication. In Proceedings of the 10th International Conference on Environment and Electrical Engineering (EEEIC), Rome, Italy, 8-11 May 2011.

14. Kai-Hui, Z.; Ming-Chao, X. Impacts of microgrid on protection of distribution networks and protection strategy of microgrid. In Proceedings of the International Conference on Advanced Power System Automation and Protection (APAP), Beijing, China, 16-20 October 2011; pp. 356-359.

15. Ustun, T.S.; Ozansoy, C.; Zayegh, A. Modeling of a Centralized Microgrid Protection System and Distributed Energy Resources according to IEC 61850-7-420. IEEE Trans. Power Syst. 2012, 27, 1560-1567. [CrossRef]

16. Damchi, Y.; Mashhadi, H.R.; Sadeh, J.; Bashir, M. Optimal coordination of directional overcurrent relays in a microgrid system using a hybrid particle swarm optimization. In Proceedings of the International Conference on Advanced Power System Automation and Protection (APAP), Beijing, China, 16-20 October 2011; pp. 1135-1138.

17. Razibul, I.M.; Gabbar, H. Study of micro grid safety and protection strategies with control system infrastructures. Smart Grid Renew. Energy 2012, 3, 1-9.

18. Oudalov, A.; Fidigatti, A. Adaptive network protection in microgrids. Int. J. Distrib. Energy Resour. 2009, 4, $201-225$.

19. Ren, F.; Zhang, M.; Soetanto, D.; Su, X. Conceptual design of a multi-agent system for interconnected power systems restoration. IEEE Trans. Power Syst. 2012, 27, 732-740. [CrossRef]

20. Xiangjun, Z.; Li, K.K.; Chan, W.L.; Sheng, S. Multi-agents based protection for distributed generation systems. In Proceedings of the IEEE International Conference on Electric Utility Deregulation, Restructuring and Power Technologies, Hong Kong, China, 5-8 April 2004; Volume 1, pp. 393-397.

21. Wan, H.; Li, K.K.; Wong, K.P. An adaptive multiagent approach to protection relay coordination with distributed generators in industrial power distribution system. IEEE Trans. Ind. Appl. 2010, 46, 2118-2124. [CrossRef]

22. Ma, J.; Wang, X.; Zhang, Y.; Yang, Q.; Phadke, A.G. A novel adaptive current protection scheme for distribution systems with distributed generation. Int. J. Electr. Power Energy Syst. 2012, 43, 1460-1466. [CrossRef]

23. Laaksonen, H.J. Protection Principles for Future Microgrids. IEEE Trans. Power Electron. 2010, 25, 2910-2918. [CrossRef]

24. Zamani, M.; Sidhu, T.; Yazdani, A. A Protection Strategy and Microprocessor-Based Relay for Low-Voltage Microgrids. IEEE Trans. Power Deliv. 2011, 26, 1873-1883. [CrossRef]

25. Bui, D.; Chen, S. Fault protection solutions appropriately proposed for ungrounded low voltage AC microgrids: Review and proposals. Renew. Sustain. Energy Rev. 2017, 75, 1156-1174. [CrossRef]

26. Bui, D.; Lien, K.; Chang, Y.; Lee, Y. Investigation on transient behaviours of a uni-grounded low-voltage AC microgrid and evaluation on its available fault protection methods-Review and proposals. Renew. Sustain. Energy Rev. 2017, 75, 1417-1452. [CrossRef]

27. Sortomme, E.; Venkata, S.S.; Mitra, J. Microgrid Protection Using Communication-Assisted Digital Relays. IEEE Trans. Power Deliv. 2010, 25, 2789-2796. [CrossRef] 
28. Jager, J.; Keil, T.; Shang, L.; Krebs, R. New protection coordination methods in the presence of distributed generation. In Proceedings of the 8th International Conference on Developments in Power System Protection, Amsterdam, The Netherlands, 5-8 April 2004.

29. Tailor, J.K.; Osman, A.H. Restoration of fuse-recloser coordination in distribution system with high DG penetration. In Proceedings of the IEEE Power and Energy Society General Meeting-Conversion and Delivery of Electrical Energy in the 21st Century, Pittsburgh, PA, USA, 20-24 July 2008; pp. 1-8.

30. Najy, W.K.; Zeineldin, H.H.; Woon, W.L. Optimal protection coordination for microgrids with grid-connected and islanded capability. IEEE Trans. Ind. Electron. 2013, 60, 1668-1677. [CrossRef]

31. Ustun, T.S.; Ozansoy, C.; Zayegh, A. A central microgrid protection system for networks with fault current limiters. In Proceedings of the 10th International Conference on Environment and Electrical Engineering (EEEIC), Rome, Italy, 8-11 May 2011; pp. 1-4.

32. Barker, P.P.; De Mello, R.W. Determining the impact of distributed generation on power systems. In Proceedings of the IEEE Summer Meeting Power Engineering Society, Seattle, WA, USA, 16-20 July 2000; pp. 1645-1656.

33. Nimpitiwan, N.; Heydt, G.T.; Ayyanar, R.; Suryanarayanan, S. Fault current contribution from synchronous machine and inverter based distributed generators. IEEE Trans. Power Deliv. 2007, 22, 634-641. [CrossRef]

34. Shuai, Z.; Shen, C.; Yin, X.; Liu, X.; Shen, Z.J. Fault Analysis of Inverter-Interfaced Distributed Generators with Different Control Schemes. IEEE Trans. Power Deliv. 2018, 33, 1223-1235. [CrossRef]

35. Wang, J.; Hamilton, R. Analysis of Transformer Inrush Current and Comparison of Harmonic Restraint Methods in Transformer Protection. In Proceedings of the 61st Annual Conference for Protective Relay Engineers, College Station, TX, USA, 1-3 April 2008.

36. KEPCO. Modeling of Geocha-Do Microgrid; Final Report; KEPCO: Daejeon, Korea, 2015. 